\title{
Experimental investigation on the deformation and failure mechanism of slope with interbedding soft and hard rocks under rainfall infiltration
}

\author{
Yafen Song ${ }^{l}$, Li Chen ${ }^{l}$, Xiaotao Zhang ${ }^{l}$, Qian Zhao ${ }^{I}$, Linlin Yu ${ }^{l}$, Jinhua Xu ${ }^{l}$ \\ ${ }^{1}$ School of Architectural Economics and Engineering Management, Hubei Business College, Wuhan, 430079, China;
}

\begin{abstract}
Taking Peng Jiawan slope in Yiba expressway as the project background, the deformation and failure mechanism of slope with interbedding of soft and hard rocks was studied on the basis of geological analysis and similarity theory. In geomechanical model test, the water infiltration softening process is used to simulate the rainfall infiltration. The result indications showed as follows: under the condition, the deformation mode of the slope is the previous sliding-tension and upper overall creep-slip, and the failure mode is overall slip failure in the sliding zone of deep soft rock. Strictly speaking, the deformation of hard rock differs from the deformation of soft rock, hard rock deforms mainly on sliding-tension and soft rock deforms mainly on overall creep-slippage. Changes of the condition of deep soft rock affect the total stability of the interbedded slope mostly.
\end{abstract}

\section{Introduction}

In recent years, Chinese national power has become increasingly powerful. As an economic accelerator, expressway construction started late, but it has developed rapidly. By 2020, Chinese expressway mileage will reach 150,000 kilometers. With the implementation of the strategies of western development and Tough battle for poverty alleviation, the construction of expressways in mountainous areas is becoming more and more popular, and it is inevitable to pass through the areas where the soft and hard rock interbedded slopes, such as red layer and metamorphic rock, are distributed. Interbedded rock slope of soft and hard rock refers to the slope composed of two or more groups of rock masses with great difference in strength into interbedded structure, which is widely distributed in southwest, northwest, central and south China ${ }^{[1]}$. After undercutting the slope, the exposed slope will be affected by rainfall infiltration, especially the soft rock layer. With the gradual strengthening of differential weathering and hydraulic action, The soft rock layer will develop into a weak rock layer that seriously affects the stability of the slope $^{[2]}$, resulting in a large number of landslide geological disasters, such as Xuanhan Tiantai Township landslide ${ }^{[3]}$, Chongqing Jiwei Mountain landslide ${ }^{[4]}$, Qinghai Plateau Longmulgou red bed landslide ${ }^{[5]}$, etc.. These disasters will bring about serious socio-economic losses. The stability of the interbedded slope of soft and hard rock is becoming an urgent problem to be solved in the engineering field.

At present, there have been many researches on the interbedded slope of soft and hard rock, but the research on its failure mechanism is mainly qualitative analysis and finite element numerical simulation. Fewer researches are focused on its intuitive system by means of physical model test. Liu Hanxiang ${ }^{[6]}$ and Li Guo ${ }^{[7]}$ had studied the ground motion response characteristics of the soft and hard rock interbed slope and the law that the horizontal and vertical response intensity decreased with the strengthening of vibration intensity through physical simulation test. $\mathrm{Wu}$ Honggang ${ }^{[5]}$ had studied the historical evolution process which was caused by the twice attenuation of red-bed rock mass strength of gaoyuan red-bed landslide in Qinghai. These existing studies were focused more on the ground motion response and rock mass materials of the interbedded soft and hard rock slope, but there is less studies of systematic and experimental research on the deformation and failure mode of the interbedded rock slope. Research of slope deformation and failure mode is the basis of slope stability analysis ${ }^{[8]}$. In-depth study on the deformation and failure mechanism of interbedded soft and hard rock slope can better analyze the stability influencing laws of this type of slope, and provide important guidance for the disposal and optimal design of this type of slope.

Based on the simplified model of typical interbedded slope of soft and hard rock which are distributing along highway of $\mathrm{YiBa}$, this paper will study the instability mechanism of the interbedded slope of soft and hard rock under the condition of the rain infiltration. Designed for the study, the physical model test would simulate the deformation and fracture of the slope under the condition of rainfall infiltration after the excavation. The study might provide reference for the following study of similar slope.

\footnotetext{
*orresponding author: Yafen Song, 791294427@qq.com
} 


\section{Slope model}

Pengjiawan ancient landslide is one typical problem slope of many soft and hard rock interbedded landslides along the Yiba Expressway. The underlying strata of the ancient landslide are interbedded with unequal thickness of sandstone and mudstone, the rock strata gently incline along the slope, and the comprehensive occurrence of the rock mass is $36^{\circ} \angle 16^{\circ}$. The strata of the slope are relatively clear, below the surface accumulation body, 0 $\sim 16.0 \mathrm{~m}$ is strongly weathered zone, the lithology is fine sandstone, $16.0 \sim 37.4 \mathrm{~m}$ is moderately weathered zone, lithology is mudstone, $37.4 \sim 63.2 \mathrm{~m}$ is moderately weathered zone, lithology is sandstone, $63.2 \sim 93.4 \mathrm{~m}$ is breeze zone, lithology is mudstone, $93.4 \sim 100.2 \mathrm{~m}$ is breeze zone, lithology is sandstone, the bottom is huge thick layer mudstone. The liangtai river is crossing the edge of the landslide which is a rain-source river. The overburden has well-developed fissures, strong permeability and poor water storage performance. In the process of highway construction, the lower edge of slope will be disturbed to some extent, and the river will also impact the lower edge of slope in seasonal changes.

\section{Experimental design}

\subsection{Similarity ratio design}

According to the size of the frame and the actual situation of the landslide prototype, the geometric similarity ratio of the model test is determined, $C=1: 126$. The prototype range of the test simulation is $176 \mathrm{~m}$ long, $176 \mathrm{~m}$ high and $25 \mathrm{~m}$ wide. According to the similarity ratio to determine some principles and the simulation range of this experiment to determine the similarity constant, $C_{l}=126, C_{\gamma}=1.64$, are selected. The similarity constant values of each correlation can be obtained from the similarity criterion, as shown in Table 1 below.

Table 1. Simulation constants of similar material test

\begin{tabular}{ccccccccccc}
\hline$C_{\sigma}$ & $C_{\varepsilon}$ & $C_{f}$ & $C_{E}$ & $C_{C}$ & $C_{\varphi}$ & $C_{\mu}$ & $C_{\tau}$ & $C_{\delta}$ & $C_{X}$ & $C_{t}$ \\
\hline 207 & 1 & 1 & 207 & 207 & 1 & 1 & 207 & 126 & 1 & 11.2 \\
\hline
\end{tabular}

In the above Table: $C_{\sigma}$ is the stress similarity constant; $C_{l}$ is the geometric similarity constant; $C_{\gamma}$ is the heavy similarity constant; $C_{\mu}$ is poisson's ratio similarity constant; $C_{\varepsilon}$ is strain similarity constant; $C_{f}$ is the similar constant of friction coefficient; $C_{\varphi}$ is the similarity constant of internal friction Angle; $C_{\varepsilon}$ is the residual strain similarity constant; $C_{\varepsilon^{c}}$ is the uniaxial limit pressure strain similarity constant; $C_{\varepsilon^{t}}$ is the similarity constant of uniaxial ultimate tensile strain; $C_{E}$ is the similar constant of elastic modulus; $C_{C}$ is the cohesion similarity constant; $C_{\bar{\sigma}}$ is the boundary stress similarity constant; $C_{R^{t}}$ is the similar constant of tensile strength; $C_{R^{C}}$ is the similar constant of compressive strength; $C_{\tau}$ is the shear strength similarity constant; $C_{\delta}$ is the displacement similarity constant; $C_{X}$ is the volume force similarity constant; $C_{\mathrm{t}}$ is the time similarity constant ${ }^{[9]}$.

\subsection{Model material selection}

The test blocks used in the model are made of barite powder, quartz sand with different particle sizes, gypsum, water, and glycerin in a certain proportion ${ }^{[10]}$. In the following Table 2 and 3, there showed the representative physical and mechanical parameters of the prototype slope material ${ }^{[11]}$ and the physical mechanical data of model material, and the corresponding test ratio . It can be seen that the similar materials selected to simulate the slope can basically meet the similarity criterion and can be used to simulate sandstone and mudstone.

Table 2. Physico-mechanical parameters of slope rocks and similar materials

\begin{tabular}{|c|c|c|c|c|c|}
\hline Rock & $\begin{array}{l}\text { Unit weight } \\
/\left(\mathrm{kN} / \mathrm{m}^{3}\right)\end{array}$ & $\begin{array}{c}\text { Compressive } \\
\text { strength } \\
\sigma_{\mathrm{cm}} / \mathrm{MPa} \\
\end{array}$ & $\begin{array}{l}\text { Similar } \\
\text { material }\end{array}$ & $\begin{array}{l}\text { Unit weight } \\
/\left(\mathrm{kN} / \mathrm{m}^{3}\right)\end{array}$ & $\begin{array}{c}\text { Compressive } \\
\text { strength } \\
\sigma_{\mathrm{cm}} / \mathrm{MPa} \\
\end{array}$ \\
\hline Sandstone & 26.7 & 28 & I class & 15.96 & 0.14 \\
\hline Mudstone & 27 & 12 & II class & 16.16 & 0.06 \\
\hline
\end{tabular}

Table 3. Slope material ratios of highwall models

\begin{tabular}{cc}
\hline $\begin{array}{c}\text { Similar } \\
\text { material }\end{array}$ & barite powder: quartz sand: gypsum: water: glycerin \\
\hline I class & $0.36: 0.469: 0.060: 0.090: 0.013$ \\
II class & $0.68: 0.220: 0.023: 0.064: 0.013$ \\
\hline
\end{tabular}

\subsection{Test procedure}

Based on the existing test conditions, this test will simulate the interbedded slope of soft and hard rock with length of $176.4 \mathrm{~m}$ and height of $176.4 \mathrm{~m}$ of Pengjiawan ancient landslide in the prototype. The dimensions corresponding to the geometric similarity coefficient on the model are $140 \mathrm{~cm}$ and $140 \mathrm{~cm}$, and are assembled with modules of uniform specifications.

The displacement observation is carried out with dial indicators. A total of 15 dial indicators measuring points (see FIG. 1 and 2) were arranged near the lower section of the valley on the back of the model body and each rock layer. Vertical displacement and horizontal displacement were measured at each measuring point.

Based on the material characteristics of the model, the influence of rainfall on the interbedded slope of soft and hard rock is simulated by water injection. The soft rocks (2 and 4 layers in FIG. 1) were respectively softened by water injection, and the displacement changes were observed by reading the table. 


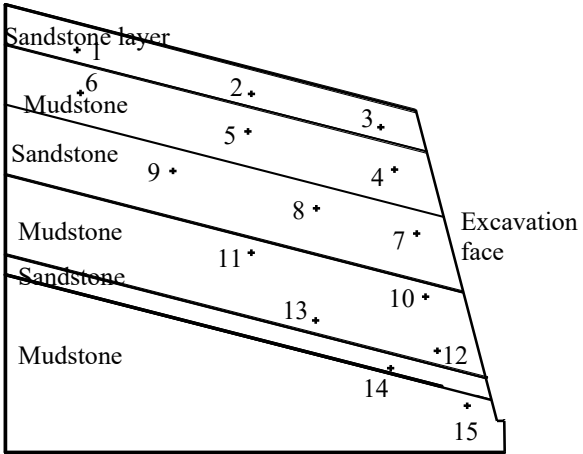

Fig. 1. Layout of displacement measuring points in model slope

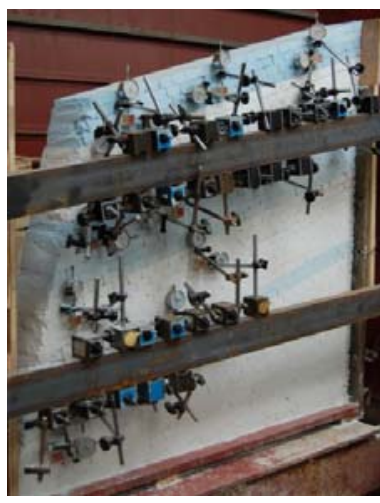

Fig. 2. Centigrade meter installation

Drip water injection method was used in the test. The test was designed to carried out by drip water injection. The whole water injection process was divided into two stages. The first stage was to inject water to the middle of the second rock layer (upper soft rock layer), and the amount of water was controlled in an average of $200 \mathrm{ml} /$ block of water per day. The second stage was kept to inject water to the middle part of the 4 th rock layer (deep soft rock layer) till the slope body stops from instability.

\section{Experimental results and analysis}

According to the water injection softening test results, the time-displacement curves of each point measured by the dial indicator in the model test are drawn, as shown in Figure 3. The number of each curve in the Figure corresponds to the number of each dial indicator. According to FIG. 3 and the failure pattern (see FIG. 4), the following rules can be obtained:

(1) In the water injection softening test, certain slip and crack deformation occurred in the early stage, and overall creep deformation occurred in the later stage. The slope was already unstable, and the failure mode was the overall slip with the deep soft rock layer as the slip plane. From the displacement time graph, the soften layer is a critical, the above ( $1 \# \sim$ \# 12) measuring point displacement is far greater than the points below (\# 13 $15 \#)$. The maximum displacement difference of horizontal displacement is $3.57 \mathrm{~mm}$, corresponding to the actual slope is $449.5 \mathrm{~mm}$. And the trailing edge of slope body is out of model framework (as shown in Figure 4 (b)), the gap is very obvious.
(2) The deformation of hard and soft rocks is different. As shown in FIG3(a)、(b), The displacement curves of the measuring points in soft strata are distributed. For example, the displacement difference between the measuring point $10 \#$ and $11 \#$ of the same soft layer is $2.11 \mathrm{~mm}$, and there are very obvious tensile cracks found in the test. The displacement curve distribution of the measured points in the hard rock layer is relatively concentrated, for example, the displacement difference between the measured points of $7 \#$ and $8 \#$ in the same hard layer is $1.33 \mathrm{~mm}$. In other words, the slip and pull deformation characteristics of the soft rock stratum are very obvious. but the hard rock stratum is not obvious. The overall creep deformation is its main deformation mode.

(3) It's the softening of deep soft rock layer that leading to the failure of slope. Figure 5 describes the displacement of the two waterflooding stage (for the convenience of observation, the displacement amplificated 5 times). From the picture it shows that the second phase of the softening layer has the faster and more significant deformation, though the two stages both occurred the slip cracking deformation. The final failure of the test is the overall slip of the deep softening layer as the sliding surface. This indicates that the thicker the overlying strata, the greater the self-weight stress, and the greater the deformation caused by the softening of the soft strata, the more adverse to the stability of the slope.

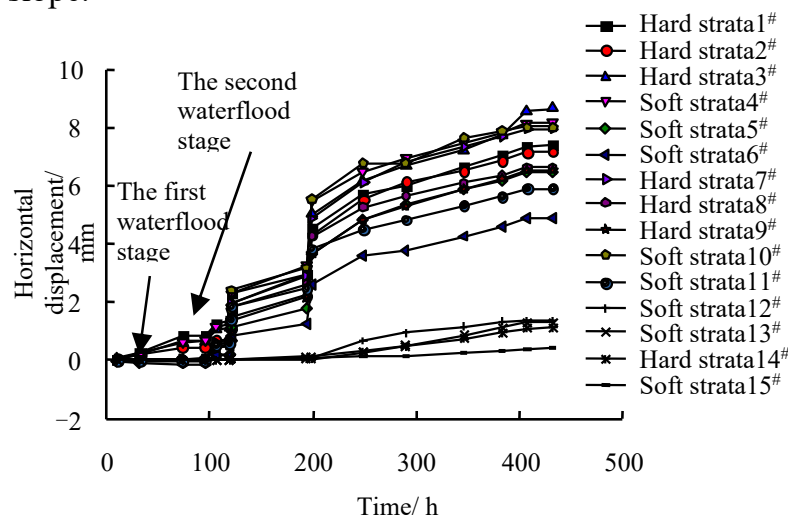

(a) Horizontal displacement-time curves of each measuring point

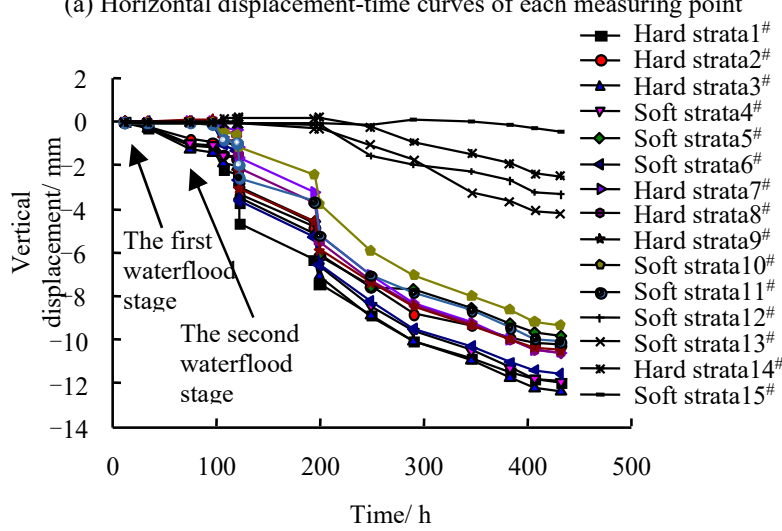

(b) Vertical displacement-time curves of each measuring point 


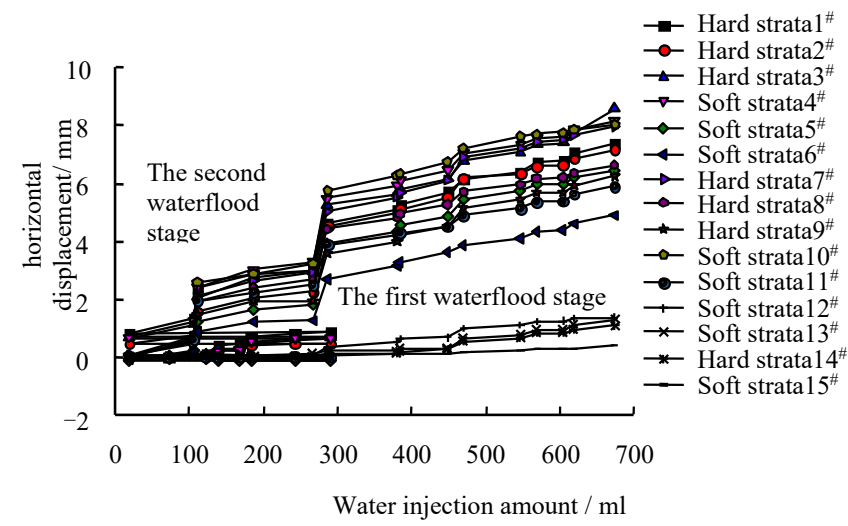

(c) Horizontal displacement-water injection curve of each measuring point

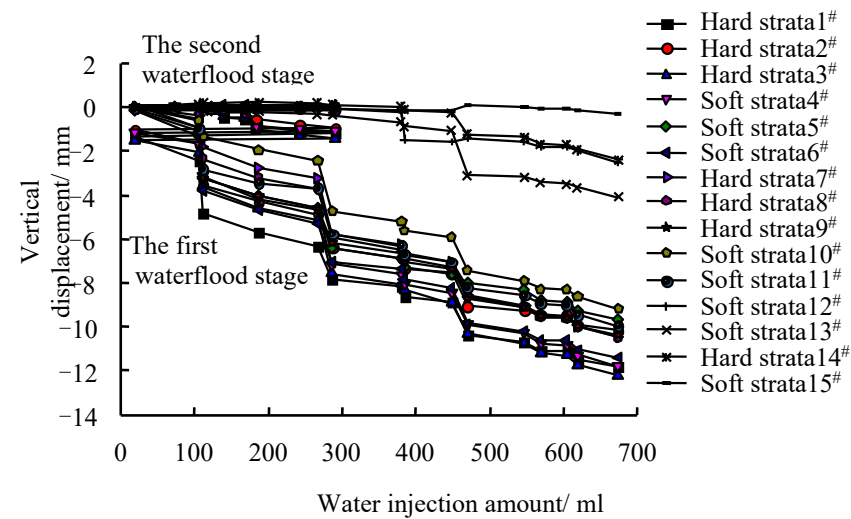

(d) The vertical displacement-water quantity relation curve of each measuring point

Fig. 3. Curves of displacement vs. times and water-injection of injection test models
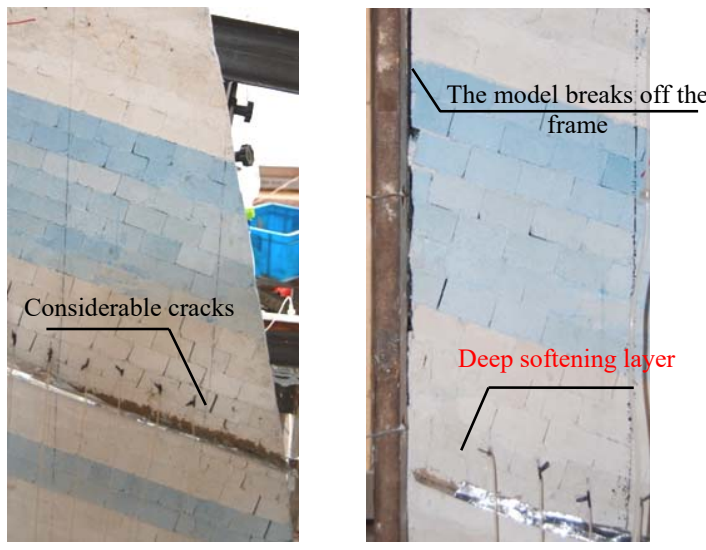

Fig.4. Failure modes of test models

\section{Conclusions}

Due to the great difference in lithology between soft rock and hard rock, the soft rock will develop into weak layer which seriously affects the stability of the slope under the action of rainfall infiltration.

Through the physical model test above, the following conclusions can be drawn:

(1) Under the softening action of rainwater, the deformation mode of this kind of soft and hard rock interbedded slope is sliding and pulling deformation in the early stage and overall creep deformation in the later stage. The failure mode is the overall slip with deep soft rock as the sliding surface.

(2) The deformation of soft rock stratum and hard rock stratum in the interbedded slope of soft and hard rock is different to a certain extent, the soft rock stratum is dominated by sliding and tensile crack deformation, while the hard rock stratum is dominated by overall creep deformation.

(3) Rainfall infiltration has an important influence on the stability of this kind of soft and hard rock interbedded slope. The open face and micro-cracks left by engineering excavation are the foundation of landslide, and water is the condition and inducement of landslide. The overall stability of the slope is more significantly affected by the state changes of the deep soft rock layer. The soft rock layer is more susceptible to external interference than the hard rock layer, and the water-bearing strength attenuation is drastic. Moreover, the thicker the overlying rock layer is, the greater the deformation of the soft rock layer is, and the lower the overall stability of the slope is.

(4) Through the study of this paper, it can be known that the safety protection of this kind of interbedded slope of soft and hard rock should focus on on-site drainage protection engineering, especially the safety protection of deep thick soft rock drainage.

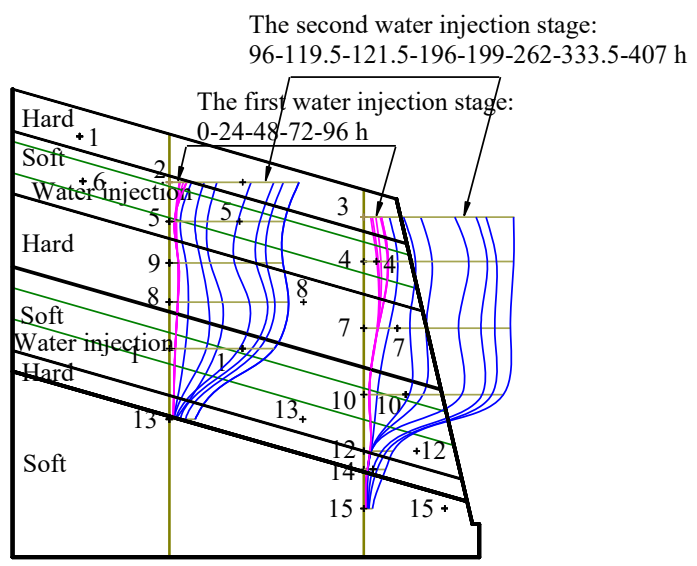

Fig.5. Curves of horizontal displacement's connection of model during water-injection test

\section{Acknowledgement}

This research was supported by Research Project of Hubei Provincial Department of Education under Grant No.B2019336 and Scientific Research Program of Hubei Business College under Grant No. KY201914.

\section{References}

1. T. Li, J. Wang. Red beds and geomor-phology types in China. Journal of Sichuan Normal University (Natural Science), 25(4), 427-431 (2002)

2. Y. Song, Failure models and instability of slopes with soft and hard rock interbedded laminated 
structure in southwest China. Chengdu University of Technology, (2011)

3. R. Huang, S. Zhao, X. Song. The formation and mechanism analysis of Tiantai landslide, Xuanhan County. Sichuan Province. Hydrogeology and Engineering Geology. 1, 13-15 (2005)

4. Q. Xu, R. Huang, Y. Yin. The Jiweishan landslide of June 5, 2009 in Wulong, Chongqing: characteristics and failure mechanism. Journal of Engineering Geology. 17(4), 433-444(2009)

5. H. Wu, H. Ma, D, Hou. Geological analysis and model experimental study of deformation mechanism of ditch-moore red bed landslide at Qinghai plateau. Chinese Journal of Rock Mechanics and Engineering. 29(10), 2091-2102 (2010)

6. H. Liu. Large scale shaking table test study on seismic response of combinational rock slopes. Chengdu University of Technology, (2011)

7. G. Li. Failure machanism of stratiform rock slope under strong earthquake. Chengdu University of Technology, (2011)
8. Y. Bian, Y. Zhang, L. Chang. Realization of slope failure pattern recognition system. Geotechnical Engineering Technique 20(3), 121-123 (2006)

9. B. Zuo, C. Chen, X. Liu. Modeling experiment study on failure mechanism of counter-tilt rock slope. Chinese Journal of Rock Mechanics and Engineering. 24(19), 3505-3511 (2005)

10. Z. Lu, Study on stability of high consequent rock slope. Institute of Rock and Soil Mechanics the Chinese Academy of Sciences. (2005)

11. K. Xia, C. Chen, Z. Lu. Analysis of stability diagram of rock bedded slope under hydraulic pressure. Rock and Soil Mechanics. 35(10), 29853040. (2014) 